\title{
Using a Low-Cost Playful Strategy to Present Sign Language on Non-Formal Educational Spaces
}

\author{
Tathianna Prado Dawes ${ }^{1,2}$, Gustavo Henrique Varela Saturnino Alves,4, \\ Helena Carla Castro ${ }^{1,3,4,5}$, Andréia Santos Silva ${ }^{4}$, Lucianne Fragel-Madeira ${ }^{1,4,5}$ \\ ${ }^{1}$ Professional Master Course in Diversity and Inclusion, CMPDI, UFF, Niterói, RJ, Brazil \\ ${ }^{2}$ Department of Classical and Vernacular Letters-Instituto de Letras, UFF, Niterói, RJ, Brazil \\ ${ }^{3}$ Post-Graduation Program in Teaching of Biosciences and Health, PGEBS, Fiocruz, Niterói, RJ, Brazil \\ ${ }^{4}$ Post-Graduation Program in Science and Biotechnology-PPBI, UFF, Niterói, RJ, Brazil \\ ${ }^{5}$ Post-Graduation Program in Sciences, Technology and Inclusion, PGCTIn, UFF, Niterói, RJ, Brazil \\ Email: tathiannadawes@id.uff.br, gh_alves@id.uff.br, lfragel@id.uff.br
}

How to cite this paper: Dawes, T. P., Alves, G. H. V. S., Castro, H. C., Silva, A. S., \& Fragel-Madeira, L. (2019). Using a Low-Cost Playful Strategy to Present Sign Language on Non-Formal Educational Spaces. Creative Education, 10, 1230-1241. https://doi.org/10.4236/ce.2019.106092

Received: April 28, 2019

Accepted: June 25, 2019

Published: June 28, 2019

Copyright $\odot 2019$ by author(s) and Scientific Research Publishing Inc. This work is licensed under the Creative Commons Attribution International License (CC BY 4.0).

http://creativecommons.org/licenses/by/4.0/

\begin{abstract}
Deaf community has struggled worldwide to have sign language (SL) accepted and recognized as their native language. Despite the importance of SL for deaf people education, when it comes to non-formal spaces, it is mostly ignored. Unfortunately deafness is sometimes seen as an "invisible" health condition with no urgent need to be attended. In this work we described a low cost playful strategy that uses adapted games to present SL in non-formal spaces. Thus, we adapted two known games (hopscotch and memory game) to approach scientific themes through using Brazilian Sign Language (LIBRAS) as the public may quick and easily learn these signs. The material was tested with the visitors of the Brazilian itinerant scientific museum center Ciências sob Tendas (Science under Tents-CST) in eight different small Brazilian cities. By targeting the use of LIBRAS through brief interaction among visitors and CST mediators, the memory game with scientific figures (e.g. microscope) and the hopscotch made of a plastic carpet with animal photos attracted the audience attention and curiosity about SL, and deaf culture. Based on these data, we suggest that this strategy may act as an initial presentation not only for the visitors but also for the non-formal spaces mediators and directors. The material may be constructed based on any non-formal space themes, also helping on explaining the place for deaf people. Therefore it may promote the knowledge about and for deaf community on these so important educational places. Finally, by using sign language, non-formal spaces may promote and contribute to awareness about deaf socio-educational needs to the whole society in an extent that formal places cannot do.
\end{abstract}




\section{Keywords}

Deafness, Sign Language, Non-Formal Education, Low-Cost

\section{Introduction}

The inclusion and teaching of deaf children in regular schools has been widely discussed as well as the quality of the education offered to them. On that matter the society still needs to better prepare its educational professionals for attending deaf individuals respectfully, not only on formal but also on non-formal spaces (Ahmed et al., 2018; Dias et al., 2014; Flores \& Rumjanek, 2015; Martins, Albres, \& Sousa, 2015; Ortega, 2017).

Deaf community has struggled worldwide to have sign language recognized by the society as important to their educational life. In order to guarantee fully deaf child development, several authors reported that communication and interaction using sign language are necessary (Brasil, 2002; de Quadros, Lillo-Martin, \& Pichler, 2013; Dias et al., 2014; Pichler, Hochgesang, Lillo-Martin, de Quadros, \& Reynolds, 2016; Strobel \& Fernandes, 1998).

Currently in Brazil, the inclusion of deaf student in regular educational system is proposed in a bilingual education mode. Thus, a two-language approach should be used in a day-to-day manner at school and social life (de Quadros et al., 2013; Dias et al., 2014; Pichler et al., 2016). According to the Brazilian law, sign language should be used by deaf students as the native language (L1) whereas the oral-hearing official language of the country (e.g. Portuguese) is the second one (L2) (Brasil, 2002). The construction of pedagogical bilingual material to meet deaf student needs is hugely encouraged in the scholar environments. In addition, teachers and these learning spaces should be prepared to attend and stimulate each deaf student to their whole potential in the context of inclusive education (Dias et al., 2014).

However, when it comes to non-formal spaces of education such as museums and itinerants scientific centers, deaf public is still forgotten not only in Brazil but also in other countries. Museums are known as non-formal educational spaces that may use educational practices involving mediators and professionals (Jacobucci, 2008; Schwan, Grajal, \& Lewalter, 2014). These spaces are very important for dissemination of science researches and data for the society (Brush, 1989).

In a non-formal educational perspective, professionals of these spaces need to be trained to present these scientific contents to the society (Shaby, Ben-Zvi Assaraf, \& Tal, 2019) and know more about SLs. These languages are based on visual/gestural perception along with body and facial expressions and present grammatical rules different from oral languages such as Portuguese. Thus, SL needs to be presented to hearing people to stimulate their use and the inclusion of deaf community into the society in all spaces, including non-formal ones (Di- 
as et al., 2014).

It is worth mentioning that in this work we defined: 1) formal education: occurs in traditional education systems, classroom spaces, laboratories, sports courts and libraries; 2) non-formal education: corresponds to the organized initiatives of learning that happen outside the educational systems and uses others spaces than regular school such as museums, shoppings, or even a club, where everyone is invited to learn, which contribute to dissemination of different topics such as those of scientific area (Table 1) (Gohn, 2006; Jacobucci, 2008).

"CiênciasSob tendas" (Science under Tents-CST) is a Brazilian itinerant science center from Federal Fluminense University. It is a non-formal learning space where public is stimulated to interact and acquire new concepts about science and technology (http://cienciassobtendas.sites.uff.br).

According to the literature, it is necessary to understand the knowledge process to stimulate a meaningful learning (Kostiainen et al., 2018; Rautiainen, Mäensivu, \& Nikkola, 2018). Interestingly, CST stimulates the public to have curiosity whereas they questioning about the new information presented. It has a varied audience, including children from schools and local communities, which had been enchanted by CST visits to these small cities

(http://cienciassobtendas.sites.uff.br).

The process of training the CST mediators to attend the public involves searching for strategies that allow expression, meaning, abstraction and logical reasoning as well as organization of thoughts and mastery of linguistic symbolization. Therefore, a CST mediator must know how to present the knowledge to the public to make it understandable (Shaby et al., 2019). This requires new ways of presentation and activities that stimulate different cognitive and linguistic areas (Marandino, 2008), especially when considering deaf people (Barral, Rodrigues-Mascarenhas, \& Rumjanek, 2017).

Currently many deaf talents in scientific areas are wasted, especially in STEM areas, by the lacking of exposure to scientific concepts or even due to previous misconceptions not corrected at schools (Dias et al., 2014; Flores \& Rumjanek, 2015). Considering that inclusive attendance of students with special needs (eg. deafness) is not a reality for much of non-formal teaching environments, it is necessary to review and rethink accessibility and the offering of educational materials on non-formal spaces. These places should guarantee this accessibility by attending deaf people specific educational needs, which are linked directly to their linguistic issues.

Table 1. Concepts of formal and non-formal education according to Gohn (2006).

\begin{tabular}{lll}
\hline TYPE & CONCEPT & SPACES \\
\hline \multirow{3}{*}{ Formal } & $\begin{array}{l}\text { occurs through specific didactical methodologies with } \\
\text { direct guidance and orientation in regulated spaces } \\
(\text { scholar spaces such as classroom, laboratories, sports } \\
\end{array}$ & $\begin{array}{l}\text { Schools, Universities, } \\
\text { courts and libraries). }\end{array}$ \\
Non-formal & $\begin{array}{l}\text { Technology Centers } \\
\text { pedagogical methodology }\end{array}$ & Museums, Centers, \\
& & Research Institutes \\
\hline
\end{tabular}


Language is one of the main instruments of the mediator to interact with the visitors of the non-formal places (Shaby et al., 2019). On that matter, it is necessary not only to sensitive the hearing public about sign language and issues related to deaf people but also prepare the mediator for attending this special public.

Visitors of Non-Formal spaces and even mediators may be interested on learning and to know more about SL if visual and interactive materials are offered and used with them. Therefore, herein we described a playful and low cost strategy for presenting SL to visitors of non-formal spaces, also contributing to awareness about deaf socio-educational needs to the society.

\section{Methods}

\section{Local-Non-formal space}

Once a month, on Fridays, from 9 am to 5 pm, CST visits cities outside the metropolitan region of Rio de Janeiro state in Brazil. Visitors are composed by a heterogeneous population, mostly school-age people. The exhibition took place at public spaces such as parks and school playgrounds. CST team consists of about 20 to 30 mediators, plus the director, who is a faculty member, and a volunteer coordinator. Before starting scientific presentations, mediators and volunteers were trained to offer maximum contents knowledge to the public (Alves, 2016).

Usually, the public of CST is approximately 400 to 500 participants per visit including children, teenagers, seniors and teachers. In the last twelve months, CST carried out eight (8) visits to different cities and locations at Rio de Janeiro state were we tested the strategy, including: Rio de Janeiro (Belford Roxo and Santa Cruz), Niterói (Center and Itaipu), Cantagalo, São Gonçalo, Rio Bonito and São Pedro da Aldeia.

CST presented several interactive presentations. One of them is called "Braille and LIBRAS" to disseminate to hearing public the importance of Brazilian Sign Language (LIBRAS) and other symbol systems (Braille) and their use to deaf or/and blind-deaf people. Thus we tested our strategy into this CST section, adding our games to their presentation space.

\section{The Interactive material}

In order to stimulate learning and curiosity of hearing people about sign language, we adapted two playful classical games (memory and hopscotch games) and named them as "Memory Game for LIBRAS" and "Hopscotch Game for LIBRAS" (Figure 1). Both games challenged hearing people to identify and learn signs about science topics and animals, respectively.

We developed the "Hopscotch Game for LIBRAS" which presented animals pictures (rabbit, dog, peacock, butterfly, spider and lion) printed on a big plastic carpet associated to cards with animals images in LIBRAS, together with an explanatory booklet to help on the strategy application (Figure 1(A) and Figure 1(B)). Differently, the memory game with scientific themes by using images such as microscope, cell, water, skeleton and heart (Figure $1(\mathrm{C})$ ). 


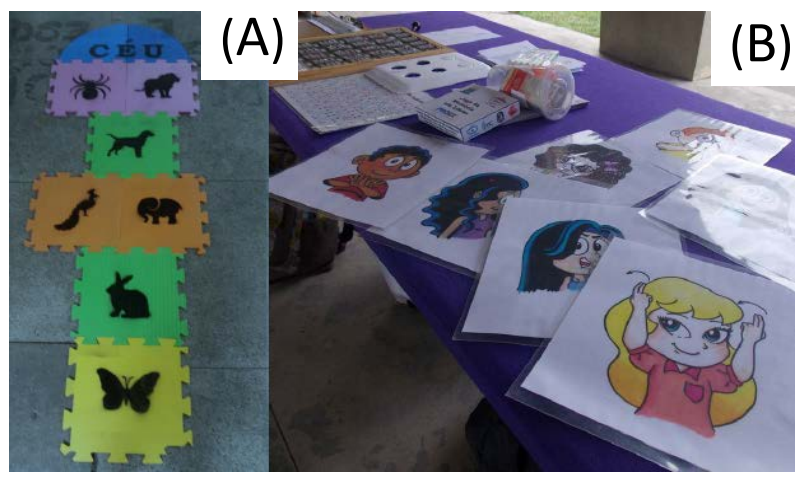

(C)

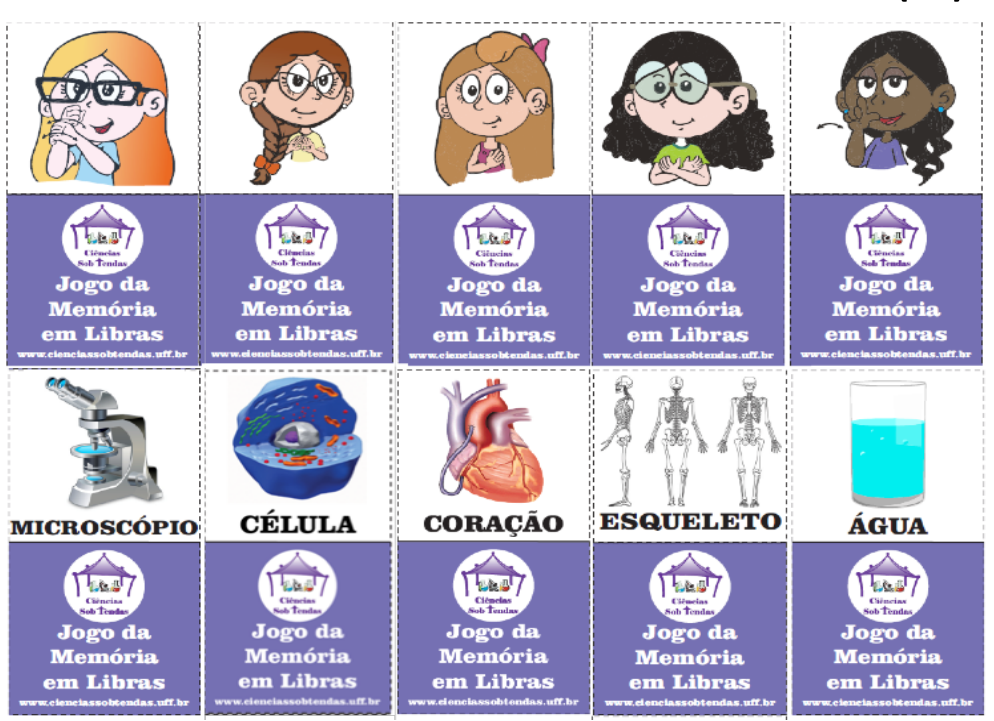

Figure 1. Low cost playful strategy for sign language presentation by adapting Hopscotch Game (A) with drawings of the animals signs in LIBRAS (B). Cards of memory game with drawings of SL (superior) and the objects in order of appearance (MICROSCÓPIO $=$ microscope; CÉLULA = cell; CORAÇÃO = heart; ESQUELETO = skeleton; ÁGUA = water). The purple part refers to the back of the card containing the game title (Jogo da Memóriaem LIBRAS = Memory game in LIBRAS), the CST logo and former website.

\section{Activities registration during CST expositions}

During the tests, we performed wide field video recordings to allow further observation of the participation and interactivity time of the public during CST's expositions. The scenes of participants making Signs during memory and hopscotch games were recorded with two digital cameras: the first one a Nikon zoom Wide 26x optical, model Coolpix L330 and the second a JVC, model HD Everio, HD memory camcorder, GZ-HM440. The cameras were placed outside the reach of participants and warnings about the presence of them were placed throughout the exhibition area.

In order to analyze the usage of LIBRAS by participants, we evaluated five parameters including: Hand Setting, Point of Articulation, Movement, Orientation and Facial and Body Expressions (Padden, Hwang, Lepic, \& Seegers, 2015). We also observed important aspects of SL grammar (iconic and arbitrary signs), 
spelling, interaction between mediator and public as well as participants behavior.

\section{Results and Discussion}

\subsection{Hopscotch Game}

In this work we tested a low-cost playful strategy with two adapted materials to present SL in eight cities visited by CST in the state of Rio de Janeiro, Brazil. The main purpose was to raise the interest of hearing public to SL as well as the awareness about the importance of communication and interaction with deaf people through this visual-gestural language.

During CST expositions we tested the "Hopscotch Game" using animals carpet. In order to play, each participant was invited to select a card with an animal signal in LIBRAS. Then the sign was taught and repeated by the participant. On the animal plastic carpet, the participant had to perform the correct sign of the animal (Figure 2).

Video recording analysis demonstrated that participants were interested in learning sign language as they noticed the characteristics of animals through signs such as: tail of the peacock, rabbit ears, dog muzzle and lion facial expression (Figure 3). Video recordings also revealed that most children had difficulty on performing the signs of "peacock" and "butterfly" probably because these signals have similar hand configuration (Figure 3).
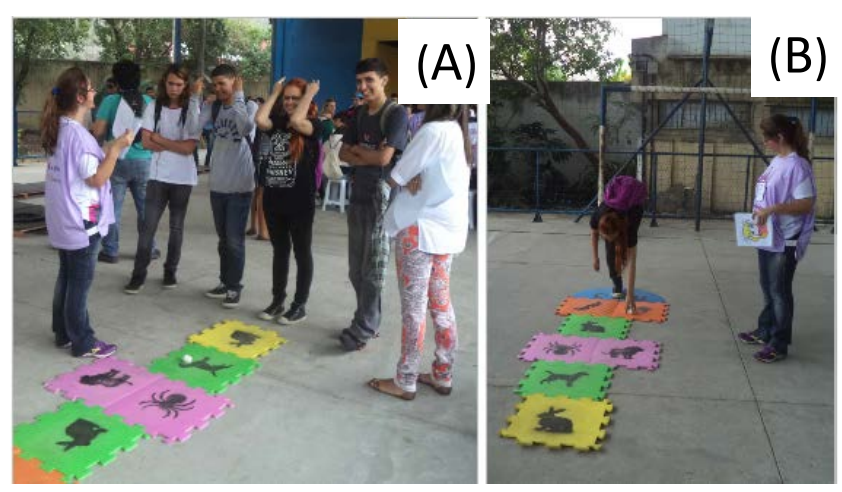

Figure 2. Test of hopscotch game during visit of CST to Itaipú, Niterói. Visitors performed the rabbit sign (A) and played in the game carpet (B).

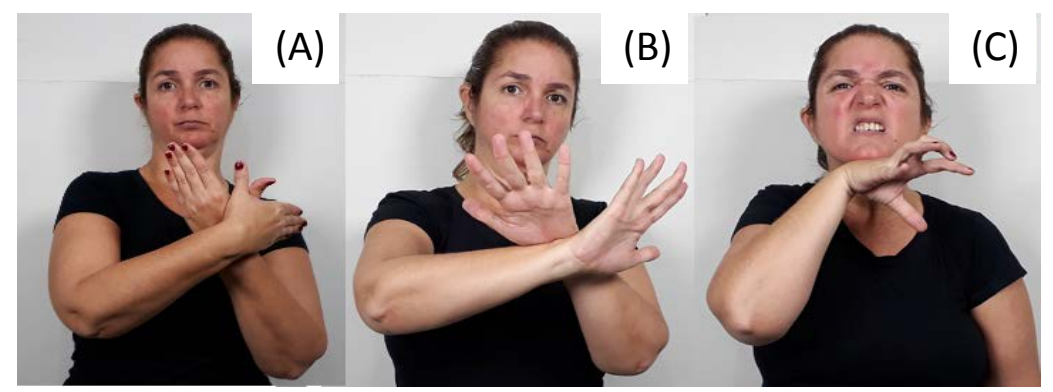

Figure 3. Most difficult signs for the visitors to perform, possibly due to similar hand position (butterfly-A and peacock-B) and use of face expression (lion-C). 
Facial and body expression can represent joy, sadness, anger, love, enchantment, generally establishing the sign meaning and one of the fundamental parameters of SL (Brito, 1995; Ferreira, Weck, da Silva, do Vale de Sousa, \& de Andrade Santos, 2011; Strobel \& Fernandes, 1998). For lion sign (Figure 3(C)), most participants did not use facial expression, whereas others demonstrated the sign of an "angry" lion. Some participants were ashamed to make the expression of a lion when it gets angry and others did not initially understand the importance of facial expression in sign language, using only the correct hand location. In order to perform lion sign, it is necessary to express a characteristic of lion whose facial expression is to cause fear. It is worthy to mention that deaf cannot hear the tone of voice but see the facial expression.

Besides the difficult on the hand positions of signs of "peacock" and "butterfly (back or front), they also presented difficulties with rabbit and horse signs (Figure 4) due to the ears rotated to the back or front, respectively.

Despite difficult on performing the sign, butterfly sign was the fastest identified by participants as it is an iconic sign as reported by Brito (1995). For this author, some signs of LIBRAS allude to the image of its meaning, as in the case of butterfly and spider. However, for some signs, mediators had to give tips such as "What is the animal that has a beautiful tail?" or "which animal has a trumpet?". After every tip, participant was asked to look for the animal on the carpet and most of them identified it with joy. Interestingly we also noticed that several groups of participants returned to play more in the hopscotch game to teach signs to another colleagues who had not played yet, calling them afterwards.

During expositions, we noticed that some participants knew sign language alphabet and tried to spelled some words such as S-P-I-D-E-R. Spelling is usually used for people's names or even for signs that do not exist. According to the author Gesser (2009) “(...) the manual alphabet has a role in the interaction among the users of the sign language. It is used to spell out people names or places, acronyms and non-existent names in sign language that does not yet have a sign (...)". In case of spider, the signal with the open hand moving forward replaces the of use dactylology. Thus we always explained to participants that not all names should be spelled in SL, and like oral languages, each oral name has its sign.

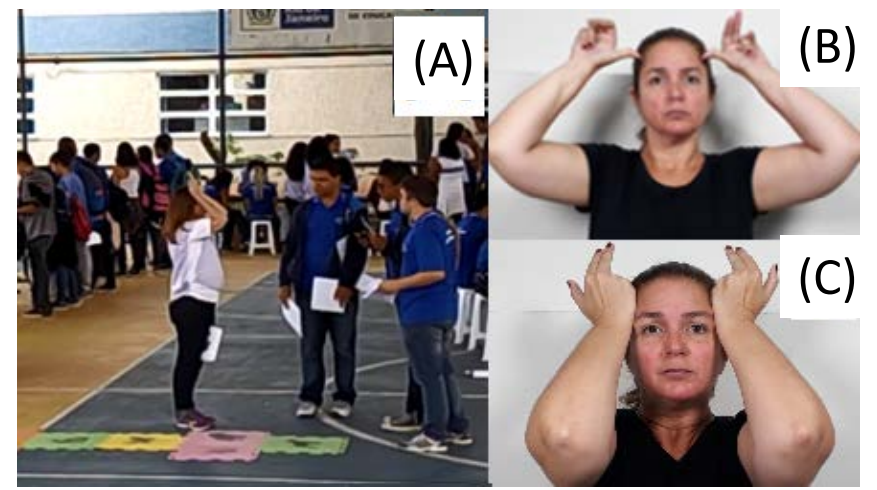

Figure 4. Hopscotch game of CST in Santa Cruz city. The mediator showing the rabbit sign (A). Differences between horse sign (B) and rabbit sign in LIBRAS (C). 
In this activity we noticed that sign language communication and interaction was really stimulated. Both students and teachers notably participated and understood the importance of SL, always with curiosity to understand the world of deaf people.

\subsection{Memory Game}

The memory game constructed with scientific theme figures (e.g. microscope, water, skeleton, heart and cells) was used to stimulate communication and interaction through LIBRAS with the public. We also offered them information about LIBRAS and deaf community that most Brazilian people have misconceptions such as deaf mute health condition and that sign language and mimicry/gesture are not the same.

Microscope was the best iconic sign, very similar to reality and many participants identified it without difficulty and still vibrated when it hit the card turned with its pair in the memory game (Figure 5).

Our playful material was constructed to allow the presentation of not only iconic but also arbitrary signs. One example is the skeleton signal (Figure 2(C)) that uses the same hand configuration of spider, but crossing the arms and without movement. This skeletal sign is identified as an arbitrary signal "that bear no resemblance to the data of reality they represent" (Strobel \& Fernandes, 1998). Overall, most participants did not identify the skeleton sign because it does not represent reality. Some performed it with their hands folded inward in front of their chest without movement whereas others cross their arms with the movement outward, as shown by the correct signal.

Among different groups and people attended, it was common to notice that some were interested on learning other signs. For example, when visiting São Pedro da Aldeiacity, a group of girls of approximately 10 - 12 years old wanted to know fish sign (Figure 6(A)). This group came back several times and asked to teach them other signs. At this point, as they were clearly interested in SL, we asked simple questions, such as "Deaf does not speak?" and "How do deaf learn sign language?", using their interest to teach them more about deaf community, also demystifying their previous misconcepts. On the same visit, a 5 years old hearing student from a public school learned "dog" sign without presenting any difficulty (Figure 6(B)). Her mother was delighted as her daughter learned easily a language that she had never seen before in her life. Thus it demonstrated that memory game aroused their curiosity to learn LIBRAS.

We also discussed the comparison between mimicry and sign language during testing the strategy, allowing participants to notice how different they are. Mimicry/gesture is a way to communicate to those who do not know SL but it has no grammar parameters or complexity levels as it is not a language (Goldin-Meadow \& Brentari, 2017). For example, mediator asked what is the heart sign and all participants made heart-shaped drawing representation. Thus the mediator explained that this is the mimicry "sign", which is similar to what we do for signing water (a cup in the mouth as we drink, which is in fact mimicry) 
(Figure 6). The mediator compared similarities between mimicry and SL also using the microscope sign that is easier to learn and identify, as it is very similar to mimic (Figure 7).

During application of games in CST expositions at all eight (8) Brazilian small cities, we detected positive feelings in most visitants, including astonishment, curiosity, surprise and several smiles, despite their different ages and interests (Figure 8). Most important, the use of this low-cost playful and interactive strategy using SL in a non-formal teaching space helped to inform them about this visual-gestural language, also allowing communication, interaction and use of the signs presented. Unfortunately we also noticed some young people worried about time, desiring to go to another workshop or when the teachers call them to leave due to bus time for return to the school. We could also observe some people doing wrong signs, with inattention, without knowledge of LIBRAS and without interest in learning the language.

\section{Final Considerations}

Herein we described a low-cost playful strategy by adapting two classical games to be used in non-formal educational environments for showing and divulgating sign language. According to our results, we contribute to the process of stimulating the communication and interaction of SL with the participating public during visits of science center Sciences under Tents, and in this way, to promote the awareness of socio-educational inclusion through the natural sciences.

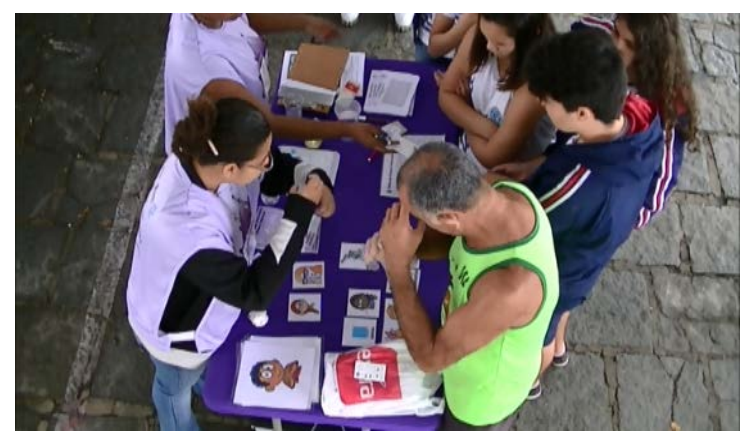

Figure 5. Demonstration of scientific memory game in LIBRAS during CST exhibition at São Pedro da Aldeia city. The elderly and the mediator doing the microscope sign.

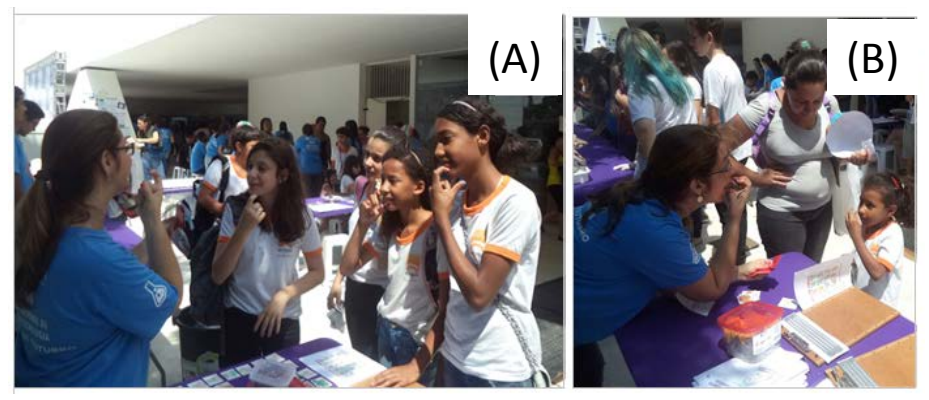

Figure 6. Adapted memory game during CST exhibition at Niterói. Visitors performing fish (A) and $\operatorname{dog}(\mathrm{B})$ signs. 


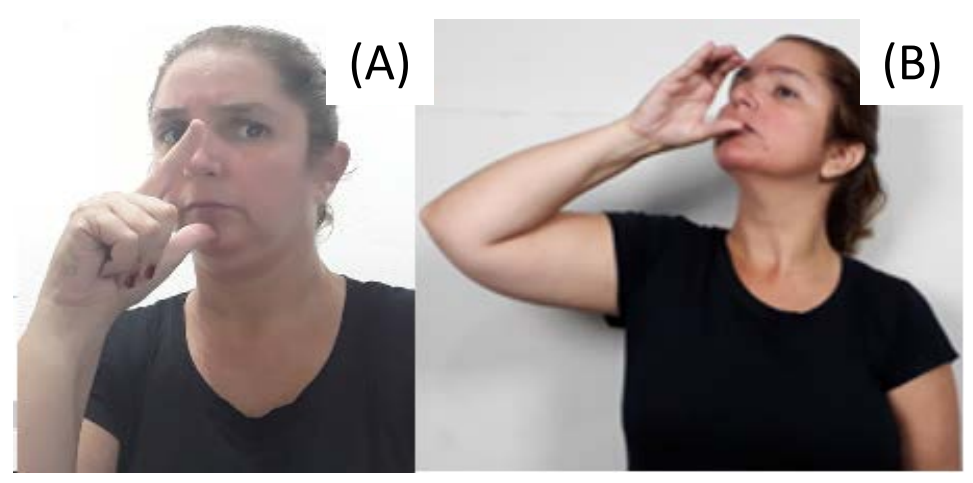

Figure 7. Water sign (A) and mimicry/gesture (B) used as examples to explain grammar features of sign languages during testing the low-cost playful strategy.

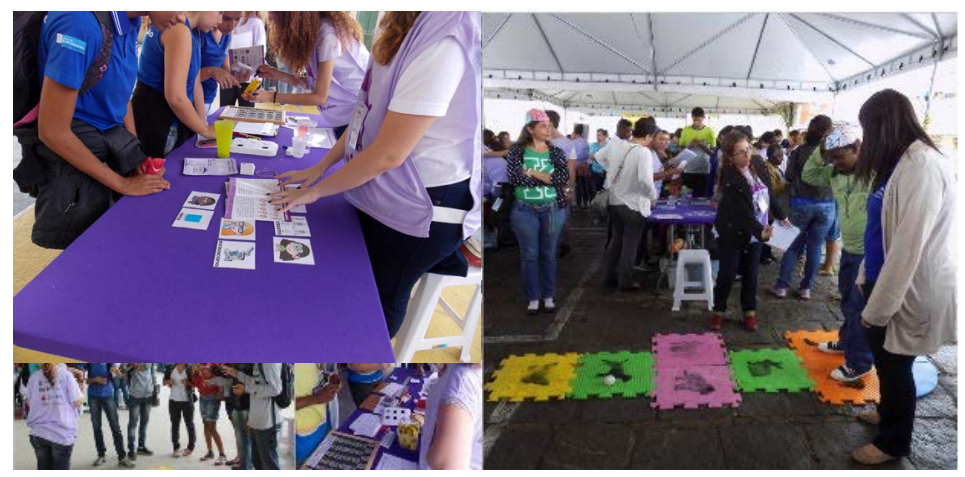

Figure 8. Different moments during testing of the low-cost playful strategy by using the adapted material on the Brazilian Cities.

With the realization of this project we notice that it is necessary to disseminate LIBRAS-Brazilian Sign Language in formal and non-formal educational environments in order to truly achieve a meaningful inclusion, leading public to have knowledge of an unknown language. The video recording analysis showed that majority of public was not aware about LIBRAS, what took them later to have interest in knowing and learning this language. In this way, the communication of SL in non-formal educational environments is traced through the implementation and dialogue among all.

We also perceive the importance of mediator's participation for exchange of information and knowledge, presenting the concepts, object sand language of LIBRAS aiming at the effectiveness of its communication and interaction among participating public.

We noticed that the use of SL in non-formal environments can be achieved when public have knowledge about this language and both communication and interaction are encouraged during the process. From the experiences with CST visitation, we recognized once more the importance of increasing the accessibility by using SL to minimize deaf community obstacles on getting access to education.

Interestingly, the playful material can be constructed based on any themes, also helping on explaining them to deaf community. Therefore it may promote 
the knowledge about and for deaf people on these so important educational places.

In conclusion, the goal of disseminating SL in non-formal educational environments is effective and needs to be expanded with more research and didactic products. Meanwhile, this strategy helps to bring these special audiences closer to these spaces and their civil rights for accessing a non-formal education.

\section{Acknowledgements}

This work was conducted during a research fellowship supported by National Council for Scientific and Technological Development (CNPq) and Carlos Chagas Filho Foundation for Research Support of Rio de Janeiro State (FAPERJ) and also scholarship by Coordination for the Improvement of Higher Education Personnel (CAPES) and Dean of Extension of Fluminense Federal University (PROEX-UFF).

\section{Conflicts of Interest}

The authors declare no conflicts of interest regarding the publication of this paper.

\section{References}

Ahmed, M. A., Zaidan, B. B., Zaidan, A. A., Salih, M. M., Lakulu, M. M. bin, Ahmed, M. A. et al. (2018). A Review on Systems-Based Sensory Gloves for Sign Language Recognition State of the Art between 2007 and 2017. Sensors, 18, 2208. https://doi.org/10.3390/s18072208

Alves, G. H. (2016). Science under Tents-Awakening to Biotechnology. Rio de Janeiro: Universidade Federal Fluminense. https://sucupira.capes.gov.br/sucupira/public/consultas/coleta/trabalhoConclusao/view TrabalhoConclusao.jsf?popup=true\&id_trabalho $=4252291$

Barral, J., Rodrigues-Mascarenhas, S., \& Rumjanek, V. (2017). Signing Science-Introducing Deaf Students to Laboratory Practice. 9th International Conference on Education and New Learning Technologies, Barcelona, Spain, 3-5 July 2017, 8903-8907. https://doi.org/10.21125/edulearn.2017.0671

Brasil (2002). Law No. 10.436, Provides on the Brazilian Sign Language-Libras and Other Measures. Brazil: Diário Oficial Da União.

Brito, L. F. (1995). By a Grammar of Sign Language. Tempo Brasileiro.

Brush, S. G. (1989). History of Science and Science Education. Interchange, 20, 60-70. https://doi.org/10.1007/BF01807048

de Quadros, R. M., Lillo-Martin, D., \& Pichler, D. C. (2013). What Bimodal Bilingual Have to Say about Bilingual Developing? Letras de Hoje, 48, 380.

Dias, L., Mariani, R., Delou, C. M. C., Winagraski, E., Carvalho, H. S., \& Castro, H. C. (2014). Deafness and the Educational Rights: A Brief Review through a Brazilian Perspective. Creative Education, 5, 491-500. https://doi.org/10.4236/ce.2014.57058

Ferreira, A. L., Weck, J. T., da Silva, J. E. F., do Vale de Sousa, M. F., \& de Andrade Santos, P. R. (2011). Learning LIBRAS: Module 2. Natal: EDUFRN.

Flores, A. C. F., \& Rumjanek, V. M. (2015). Teaching Science to Elementary School Deaf 
Children in Brazil. Creative Education, 6, 2127-2135.

https://doi.org/10.4236/ce.2015.620216

Gesser, A. (2009). Pounds? What Language Is That? Children and Prejudices around Sign Language and Deaf Reality. Parábola Ed.

Gohn, M. da G. (2006). Non-Formal Education in Social Pedagogy. In Proceedings of the 1. I Congresso Internacional de Pedagogia Social. Brasil: SciELO.

Goldin-Meadow, S., \& Brentari, D. (2017). Gesture, Sign, and Language: The Coming of Age of Sign Language and Gesture Studies. Behavioral and Brain Sciences, 40, e46. https://doi.org/10.1017/S0140525X15001247

Jacobucci, D. F. C. (2008). Contributions of Non-Formal Spaces of Education for the Formation of Scientific Culture. Em Extensão, 7.

Kostiainen, E., Ukskoski, T., Ruohotie-Lyhty, M., Kauppinen, M., Kainulainen, J., \& Mäkinen, T. (2018). Meaningful Learning in Teacher Education. Teaching and Teacher Education, 71, 66-77. https://doi.org/10.1016/j.tate.2017.12.009

Marandino, M. (2008). Education in Museums: Mediation in Focus. São Paulo: Geenf/FEUSP.

Martins, V. R. de O., Albres, N. de A., \& Sousa, W. P. de A. (2015). Early Childhood Education Assistance and Play in Language Acquisition for Deaf Children. Pro-Posições, 26, 103-124. https://doi.org/10.1590/0103-7307201507805

Ortega, G. (2017). Iconicity and Sign Lexical Acquisition: A Review. Frontiers in Psychology, 8, 1280. https://doi.org/10.3389/fpsyg.2017.01280

Padden, C., Hwang, S., Lepic, R., \& Seegers, S. (2015). Tools for Language: Patterned Iconicity in Sign Language Nouns and Verbs. Topics in Cognitive Science, 7, 81-94. https://doi.org/10.1111/tops.12121

Pichler, D. C., Hochgesang, J. A., Lillo-Martin, D., de Quadros, R. M., \& Reynolds, W. (2016). Best Practices for Building a Bimodal/Bilingual Child Language Corpus. Sign Language Studies, 16, 361-388. https://doi.org/10.1353/sls.2016.0007

Rautiainen, M., Mäensivu, M., \& Nikkola, T. (2018). Becoming Interested during Teacher Education. European Journal of Teacher Education, 41, 418-432. https://doi.org/10.1080/02619768.2018.1462329

Schwan, S., Grajal, A., \& Lewalter, D. (2014). Understanding and Engagement in Places of Science Experience: Science Museums, Science Centers, Zoos, and Aquariums. Educational Psychologist, 49, 70-85. https://doi.org/10.1080/00461520.2014.917588

Shaby, N., Ben-Zvi Assaraf, O., \& Tal, T. (2019). An Examination of the Interactions between Museum Educators and Students on a School Visit to Science Museum. Journal of Research in Science Teaching, 56, 211-239. https://doi.org/10.1002/tea.21476

Strobel, K. L., \& Fernandes, S. (1998). Linguistic Aspects of LIBRAS. PR, SEC. 